\title{
Reversal learning in Drosophila larvae
}

\author{
Nino Mancini, ${ }^{1}$ Sia Hranova, ${ }^{2}$ Julia Weber, ${ }^{1}$ Aliće Weiglein, ${ }^{1}$ Michael Schleyer, ${ }^{1}$ \\ Denise Weber, ${ }^{2}$ Andreas S. Thum, ${ }^{2}$ and Bertram Gerber ${ }^{1,3,4}$ \\ ${ }^{1}$ Department of Genetics, Leibniz Institute for Neurobiology (LIN), 39118 Magdeburg, Germany; ${ }^{2}$ Institute for Biology, University of \\ Leipzig, 04103 Leipzig, Germany; ${ }^{3}$ Institute for Biology, Otto von Guericke University, 39106 Magdeburg, Germany; ${ }^{4}$ Center for \\ Behavioral Brain Sciences (CBBS), 39106 Magdeburg, Germany
}

\begin{abstract}
Adjusting behavior to changed environmental contingencies is critical for survival, and reversal learning provides an experimental handle on such cognitive flexibility. Here, we investigate reversal learning in larval Drosophila. Using odor-taste associations, we establish olfactory reversal learning in the appetitive and the aversive domain, using either fructose as a reward or high-concentration sodium chloride as a punishment, respectively. Reversal learning is demonstrated both in differential and in absolute conditioning, in either valence domain. In differential conditioning, the animals are first trained such that an odor $A$ is paired, for example, with the reward whereas odor $B$ is not $(A+/ B)$; this is followed by a second training phase with reversed contingencies $(A / B+)$. In absolute conditioning, odor $B$ is omitted, such that the animals are first trained with paired presentations of $A$ and reward, followed by unpaired training in the second training phase. Our results reveal "true" reversal learning in that the opposite associative effects of both the first and the second training phase are detectable after reversed-contingency training. In what is a surprisingly quick, one-trial contingency adjustment in the Drosophila larva, the present study establishes a simple and genetically easy accessible study case of cognitive flexibility.
\end{abstract}

[Supplemental material is available for this article.]

Change is one of the few constancies in nature. For higher animals at least, attuning functional connectivity to changed environmental contingencies can be intrinsically rewarding, a "quenching of informational thirst" that has been formalized as minimization of prediction error (Kaplan and Oudeyer 2007; Marvin and Shohamy 2016). Obviously, however, the result of such an adaptation needs to be adaptable itself: what has just been learned to be right can turn out to be wrong shortly afterwards. For the analysis of such cognitive flexibility and its distortions, reversal learning (Pavlov 1927) is a particularly fruitful paradigm (e.g., Stalnaker et al. 2009; Brigman et al. 2010; Izquierdo and Jentsch 2012; Gruner and Pittenger 2017). A reversal learning paradigm can consist of a first training phase during which the animals learn that a cue A predicts a reward to occur whereas a cue B predicts that the reward will not occur $(A+/ B)$, followed by a second training phase during which these contingencies are reversed $(\mathrm{A} / \mathrm{B}+)$. In a simplified version of such a differential conditioning paradigm, reversal learning can also be studied by omitting cue $\mathrm{B}$, in what is called absolute conditioning. Indeed, various forms of reversal learning paradigm have been used across sensory modalities and valence domains in vertebrates and invertebrates, including worms, molluscs, and insects such as the honeybee Apis mellifera (Young 1962; Jacobson 1963; Rajalakshmi and Jeeves 1965; Giurfa 2003; Izquierdo et al. 2017) and the fruit fly Drosophila melanogaster (Tully and Quinn 1985; Tully et al. 1990; Ren et al. 2012; Wu et al. 2012; Chouhan et al. 2015). In the present study, we develop an experimental strategy to study olfactory reversal learning in the Drosophila larva, an emerging study case for neurobiology and the behavioral sciences (Mayford and Kandel 1999; HelfrichFörster 2004; Cobb et al. 2008; Reaume and Sokolowski 2011; Gomez-Marin and Louis 2012; Diegelmann et al. 2013; Almeida-Carvalho et al. 2017; Kohsaka et al. 2017; Clark et al.

\section{Corresponding authors: Nino.Mancini@lin-magdeburg.de; Bertram. Gerber@lin-magdeburg.de}

Article is online at http://www.learnmem.org/cgi/doi/10.1101//m.049510.119.
2018; Widmann et al. 2018; Thum and Gerber 2019). We implement reversal learning using odors as predictive cues and tastants as ecologically valid appetitive and aversive reinforcers (Gerber and Hendel 2006; Schleyer et al. 2015; Widmann et al. 2016). Given the numerical simplicity of the larval nervous system, the present paradigm will be useful for mapping reversal learning to identified circuitry (Rohwedder et al. 2016; Eichler et al. 2017; Saumweber et al. 2018) and revealing genetic modulators of cognitive flexibility.

\section{Results}

\section{Drosophila larvae adapt to changes in odor-reward contingency}

Our initial procedure consisted of a first training phase and a first test, followed by a second training phase with reversed contingencies and a second test (Fig. 1; Materials and Methods).

During the first training phase, one cohort of $\sim 30$ larvae received paired odor-reward training. This involved placing them in the middle of a Petri dish with fructose added as a reward to the agarose substrate $(+)$, and presenting the odor $n$-amyl acetate (AM, evaporating from custom-made perforated Teflon containers). After $2.5 \mathrm{~min}$ the larvae were transferred to a fresh agarose Petri dish with plain agarose but no reward and empty (EM) odor containers $(\mathrm{AM}+/ \mathrm{EM}$ training). Another cohort of larvae was trained reciprocally, that is, with unpaired presentations of the odor and the reward (AM/EM+ training). As reviewed by Schleyer et al. (2018), paired and unpaired training establish memories of

\footnotetext{
(C) 2019 Mancini et al. This article is distributed exclusively by Cold Spring Harbor Laboratory Press for the first 12 months after the full-issue publication date (see http://learnmem.cshlp.org/site/misc/terms.xhtml). After 12 months, it is available under a Creative Commons License (Attribution-NonCommercial 4.0 International), as described at http://creativecommons.org/licenses/by-nc/ $4.0 \%$.
} 
A
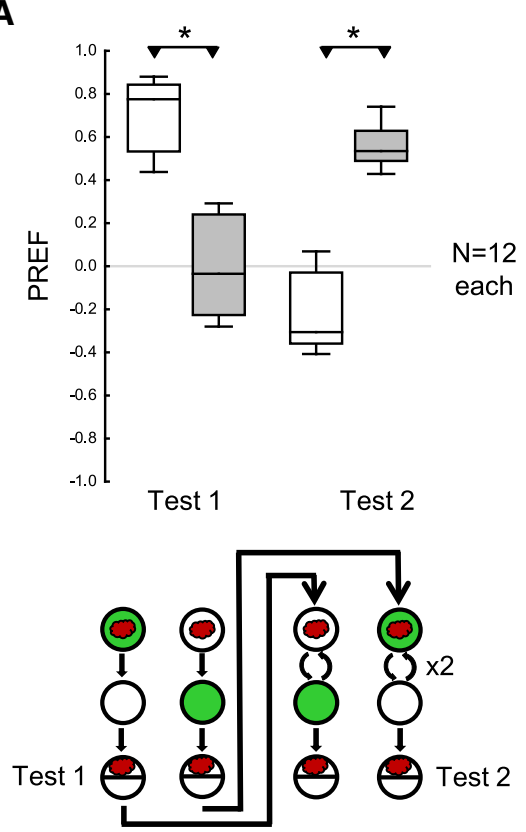

C

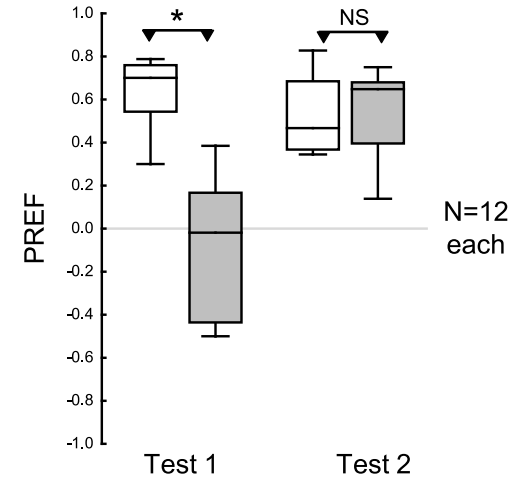

Test 1

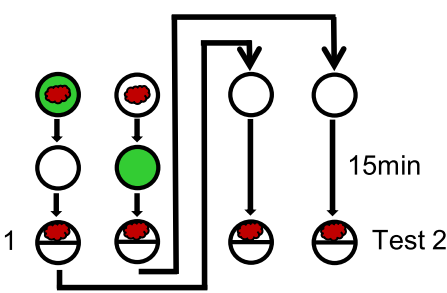

B
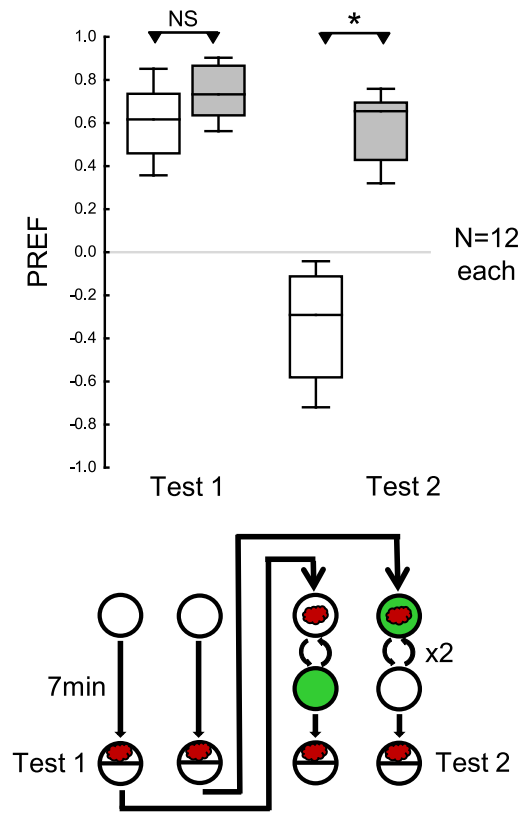

D

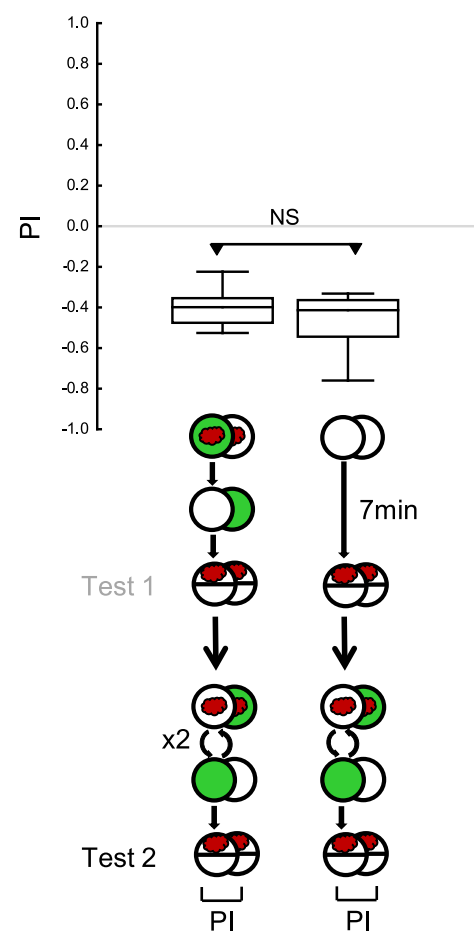

Figure 1. Drosophila larvae adapt to changes in odor-reward contingency. $(A)$ One group of stage 3 larvae received paired odor-reward training; that is, they were exposed to the odor $n$-amyl acetate (red cloud) on a Petri dish with an agarose substrate with a fructose reward added (green fill of Petri dish), and then transferred to a Petri dish with just the agarose substrate (white fill of Petri dish) and no odor. The second group of larvae was trained reciprocally, that is, with unpaired presentations of the odor and the reward. After one such training cycle there followed the first test of odor preference (Test 1 ), and a second training phase with two cycles of training with reversed contingencies of the odor and the reward. Then, the larvae were tested again for their odor preference (Test 2). In the first test, the larvae showed higher levels of odor preference after paired than after unpaired training. This pattern of results was reversed during the second test. Thus, after the first training phase, the larvae behaved according to the odor-reward contingencies during the first training phase, whereas after the second training phase their behavior was largely in accordance with the reversed contingencies in the second training phase. (B) As in A, except that the first training phase was replaced by a waiting period of $7 \mathrm{~min}$ on a Petri dish with just the agarose substrate. The larvae showed equal levels of odor preference in the first test. In the second test, they behaved according to the odor-reward contingencies during the second training phase. (C) As in A, except that the second training phase was replaced by a waiting period of $15 \mathrm{~min}$ on a Petri dish with just the agarose substrate. In the first test, the larvae behaved according to the odor-reward contingencies during the first training phase; this effect had vanished by the time of the second test. $(D)$ Performance indices $(\mathrm{PI})$ calculated from the difference in preference scores between paired versus unpaired training, for the second test of the experiments shown in $A$ (left plot) and $B$ (right plot), respectively. Negative PI scores indicate appetitive associative memory in accordance with the second training phase. Pls are equal regardless of whether or not there had been odor-reward training during the first training phase. This conforms to the conclusion from $C$ that there was no measurable impact of the first training phase on larval behavior during the second test. Data are displayed as box plots, the middle line showing the median, the box boundaries the $25 \%$ and $75 \%$ quantiles, and the whiskers the $10 \%$ and $90 \%$ quantiles. Sample sizes are given within the figure. ${ }^{*}$ and NS refer to MWU comparisons between groups $\left({ }^{*} P<0.05\right.$ corrected according to Bonferroni-Holm and NS $\left.P>0.05\right)$. 
opposite "sign": paired training establishes AM as a predictor of the occurrence of a reward, whereas unpaired training establishes AM as a predictor of the nonoccurrence of the reward. After one such training cycle, the first test of odor preference was performed. To this end, the larvae were placed in the center of a fresh, plain agarose Petri dish with an AM odor container on one side, and an empty EM container on the other side. After 3 min the number of larvae on the AM side, the EM side, as well as in a neutral middle zone $(10 \mathrm{~mm})$ was counted and the preference for AM was calculated (PREF) (Equation 1; Materials and Methods). Appetitive associative memory is indicated by a relatively higher preference for AM after $\mathrm{AM}+/ \mathrm{EM}$ training compared with the reciprocal AM/EM+ training. These differences in AM preference were then quantified by the associative performance index (PI) (Equation 2; Materials and Methods). Note that, according to the convention, appetitive associative memory for the first training phase is revealed by positive PI values.

Immediately following the first test, a second training phase was performed in which the contingencies were reversed, such that animals that had received AM+/EM training in the first phase were now trained $\mathrm{AM} / \mathrm{EM}+$, and those initially trained $\mathrm{AM} / \mathrm{EM}+$ were now trained AM+/EM. This second training phase, consisting of two training cycles, was followed by a second odor preference test. Importantly, according to convention and to emphasize the opposite effects of the first and the second training phase, appetitive associative memory for the second training phase is revealed by negative PI values (Equation 3; Materials and Methods).

In the first test, the larvae showed higher levels of odor preference after paired than after unpaired training (Fig. 1A), confirming that one cycle of such training is sufficient to establish associative odor memory (Widmann et al. 2016; Weiglein et al. 2019). This pattern was reversed after the second training phase, that is, in the second test the larvae behaved according to the odor-reward contingency during the second training phase (Fig. 1A). The ease of this reversal was striking, compared with what has been observed, for example, in experiments with honeybees (Ben-Shahar et al. 2000; Komischke et al. 2002; Hadar and Menzel 2010; Mota and Giurfa 2010; Boitard et al. 2015; Cabirol et al. 2018). We therefore wondered whether memory for the first training phase persists until the second test.

To address this question, we omitted the first training phase and merely placed the larvae onto agarose Petri dishes with neither odor nor reward. As expected, the larvae showed equal levels of odor preference in the first test, as they had not yet received any differential treatment during the experiment (Fig. 1B). Also as expected, in the second test the larvae behaved according to the odor-reward contingency during the second training phase (Fig. 1B). Critically, the PIs calculated from the preference scores during the second test are equal regardless of whether or not there had been odor-reward training during the first training phase (Fig. 1D). In a further experimental condition, we omitted the second training phase, substituting it with a waiting period during which the larvae were placed onto agarose Petri dishes with neither odor nor reward (Fig. 1C). As expected, in the first test the larvae behaved according to the first training phase, an effect that did not persist until the second test, however (Fig. 1C).

These results suggest that the experience during the first training phase no longer had a measurable impact on larval behavior during the second test. Rather, the results indicate that larvae adapt to changed environmental contingencies through rapid memory decay and/or extinction, combined with rapid learning of the new contingency. We therefore explored whether increasing the amount of training in the first training phase while decreasing it in the second training phase could uncover "true" reversal learning, that is, evidence for a process in which a persisting effect from the first training phase confronts the animals with a contin- gency contradictory to what they experience during the second training phase.

\section{Modification of the procedure for better detectability of first training phase memory}

We trained the larvae as before, except that three cycles of training were applied in the first training phase and only a single cycle of training in the second training phase (Fig. 2A,D). As in the previous experiment, the larvae behaved according to the second training phase during the second test (Fig. 2A,B). In addition, this experiment provided mixed evidence for a persisting effect from the first training phase during the second test. On the one hand, odor preferences during the second test were indistinguishable (Fig. 2C; Supplemental Fig. S1A) or were only slightly higher (Supplemental Fig. S1B) after the larvae had received paired versus unpaired training in the first training phase, suggesting that there is little if any memory left from the first training phase at this time point. On the other hand, the PI during the second test suggest a persisting effect from the first training phase (Fig. 2D): the PI were less negative when the larvae had received first and second training with opposite contingencies as compared with an omission of the first training phase.

Given this mixed evidence, we next asked whether omitting the first test would make the effects of the first training phase more easily detectable since the first test can be regarded as an extinction trial for the first training phase. Under these conditions, the memory from the first training phase was revealed both by higher odor preferences in the paired than in the unpaired group during the single test (Fig. 3A), and by significantly positive PI (Fig. 3B). In our follow-up experiments, we, therefore, decided to omit the first test throughout.

Nonetheless, we judged the remaining memory for the first training phase to be rather weak (Fig. 3B). We suspected that this may be because maintaining the animals on an agarose Petri dish between the end of training and the test provides a very similar context to that during training, such that interference with the target memories might have taken place. For the following experiment, the larvae were therefore kept either on an agarose Petri dish or in a water droplet on an empty Petri dish lid, a context that is more distinct from the one during training. Odor preferences were higher for the paired-trained than for the unpaired-trained groups in either case (Fig. 4A). Importantly, the PI revealed stronger memory when the animals were kept in the water droplet (Fig. 4B). We, therefore, used this procedure for the following appetitive reversal learning experiments.

\section{Appetitive reversal learning in larval Drosophila}

Larvae were tested either (i) after one-phase training, (ii) after twophase training with reversed contingencies in the first and the second training phase, (iii) after omitting the first training phase, or (iv) after omitting the second training phase (Fig. 5A,B). PIs after reversed-contingency training were less negative than when the first training phase was omitted, suggesting a persisting impact from the first training phase (Fig. 5B). In turn, after reversedcontingency training, the PIs were more negative than when the second training phase was omitted, suggesting behavior in accordance with the second training phase (Fig. 5B). The fact that the PI after reversed-contingency training were significantly negative and that the PI were significantly positive when the second training phase was omitted confirms these conclusions (Fig. 5B). Thus, PIs after reversed-contingency training reflect the effects of both the first and the second training phase (for a conceptual replication with shortened training trial durations see Supplemental Fig. S2). 
A
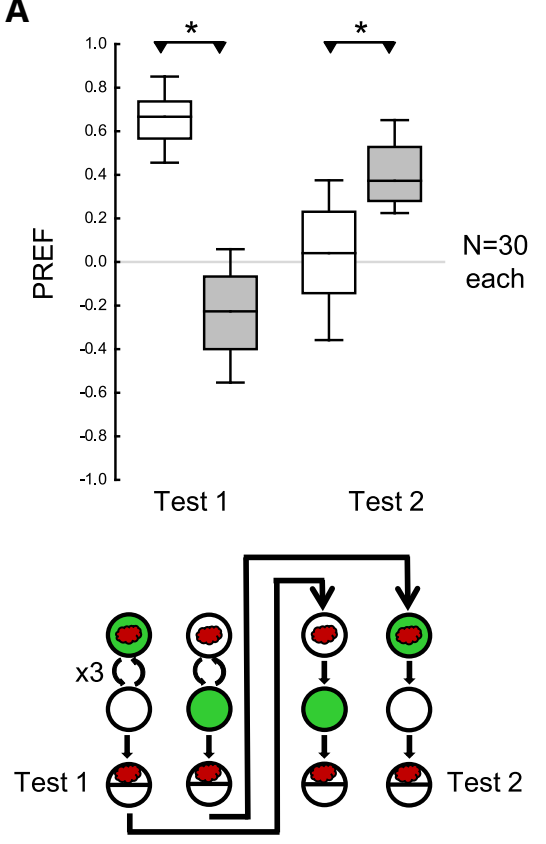

C
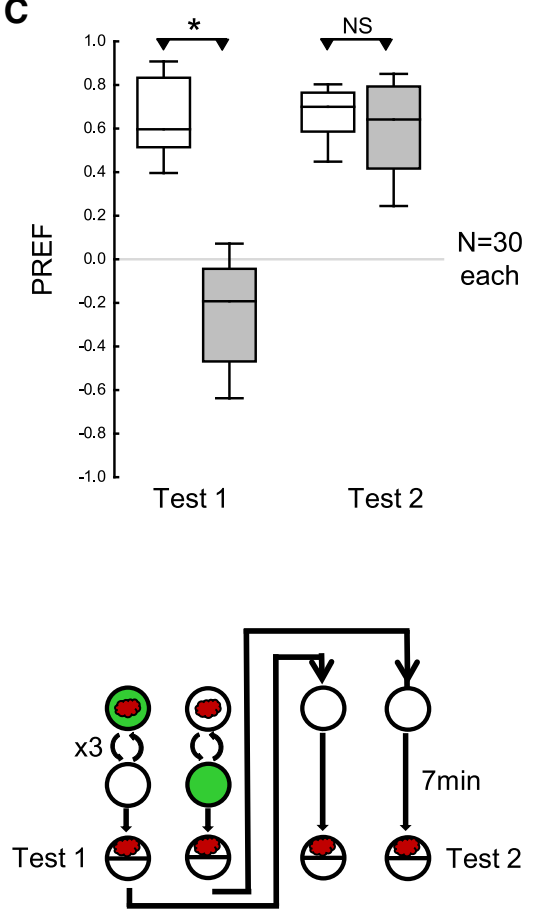

B
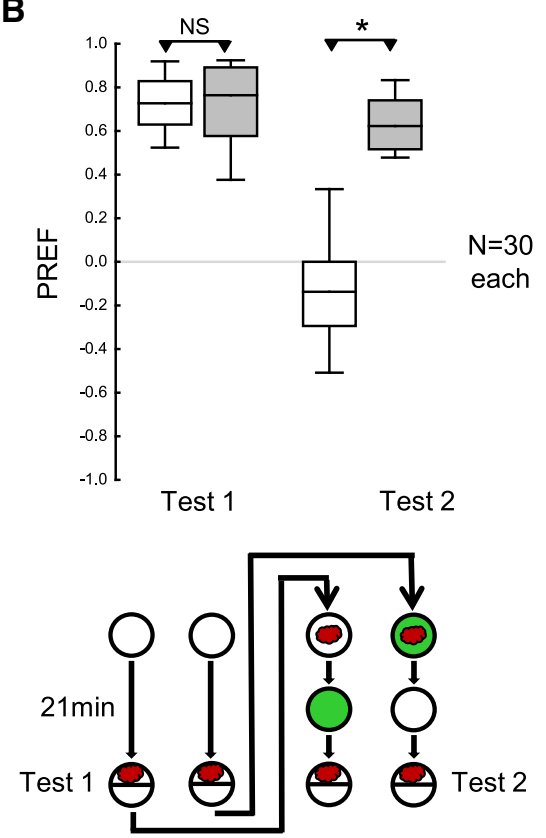

D

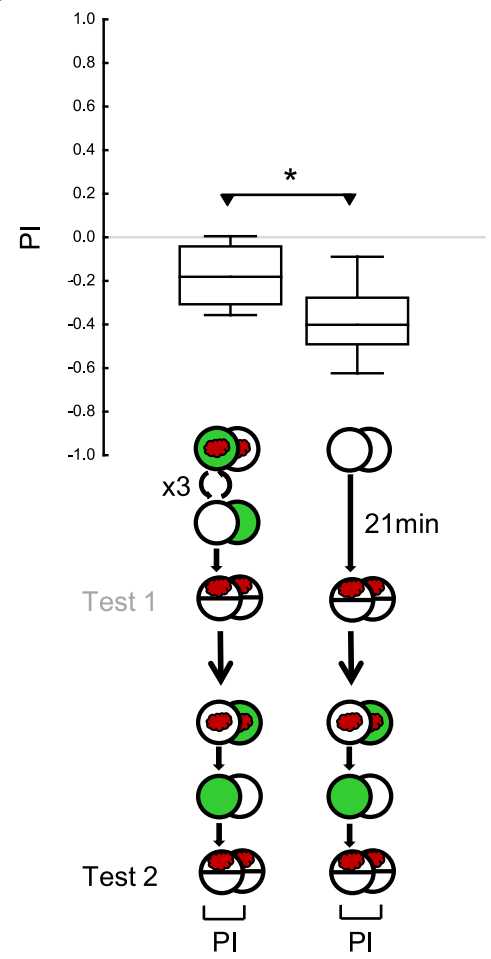

Figure 2. Modification of the procedure allows memory for the first training phase to be detected. The larvae were trained and tested as in Figure 1 , except that three cycles of training were given in the first training phase, and only a single cycle of training in the second training phase. $(A)$ The larvae received three cycles of either paired odor-reward training or unpaired presentations of the odor and the reward, followed by the first test of odor preference (Test 1); then they received a second training phase with one cycle of training with reversed contingencies of the odor and the reward, followed by a second test of odor preference (Test 2). After the first training phase, the larvae behaved according to the odor-reward contingencies during the first training phase, whereas after the second training phase their behavior was largely in accordance with the reversed contingencies in the second training phase. (B) As in $A$, except that the first training phase was replaced by a 21 min waiting period. The larvae showed equal odor preference in the first test. In the second test, they behaved according to the odor-reward contingencies during the second training phase. (C) As in $A$, except that the second training phase was replaced by a 7 min waiting period. In the first test the larvae behaved according to the odor-reward contingencies during the first training phase; this effect had vanished by the time of the second test. $(D)$ PI calculated from the difference in preference scores between paired versus unpaired training, for the second test of the experiments shown in $A$ (left plot) and $B$ (right plot), respectively. Negative PI scores indicate appetitive associative memory in accordance with the second training phase. Pls are less negative for larvae that had received odor-reward training during the first training phase, showing a residual associative effect of the training during that phase. Sample sizes are given within the figure. * and NS refer to MWU comparisons between groups ( ${ }^{*} P<0.05$ corrected according to Bonferroni-Holm and NS $P>0.05$ ). Other details as in Figure 1. 
A
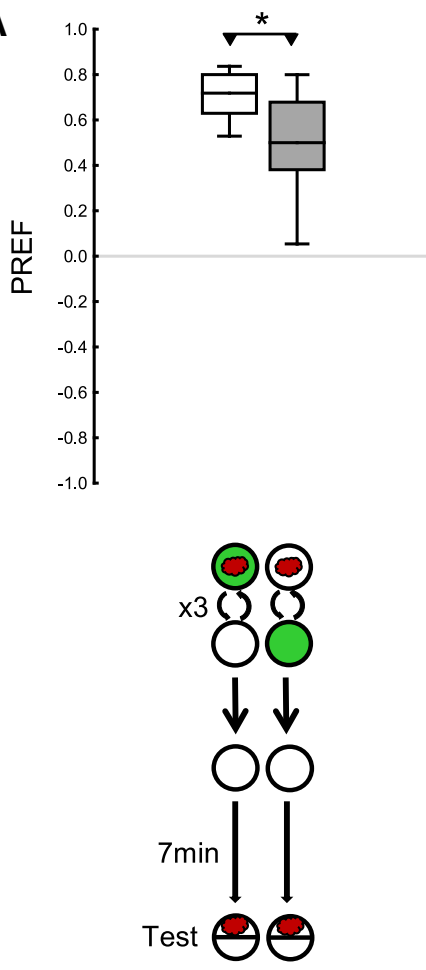

A
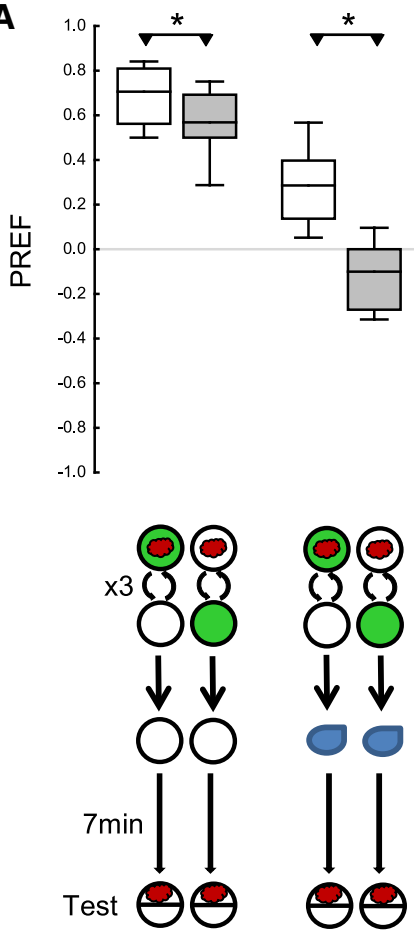

$\mathrm{N}=30$

each

B
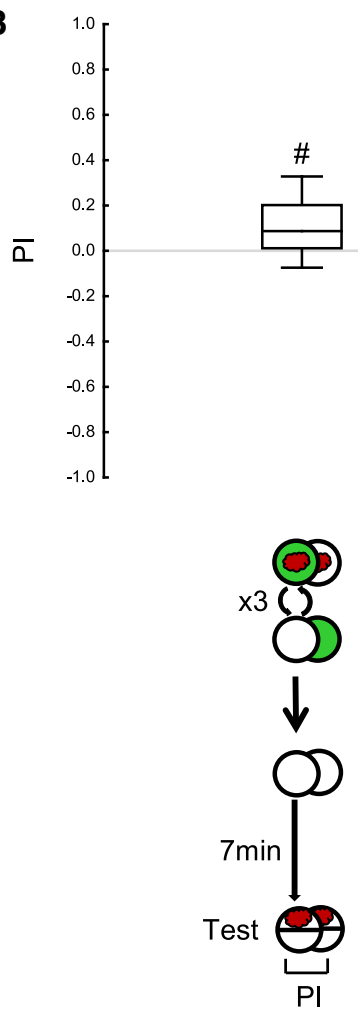

$\mathrm{N}=20$

each
B

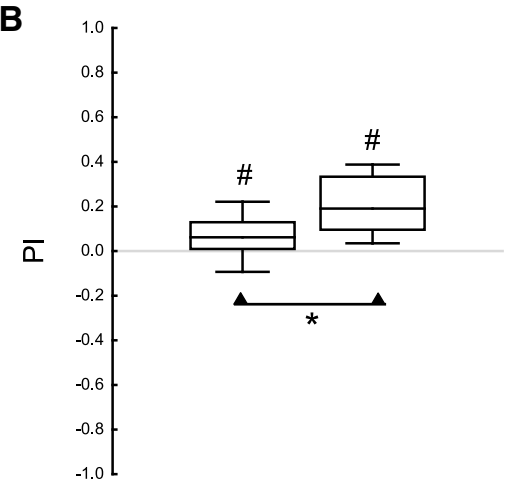

Figure 4. The context of the waiting period influences the detectability of memory for the first training phase. The larvae were trained and tested as in Figure 3, with a further experimental group for which the context during the waiting period between training and testing was implemented in a different way. $(A, B)$ The larvae received three cycles of either paired odor-reward training or unpaired presentations of the odor and the reward, followed by a $7 \mathrm{~min}$ waiting period and then a test for their odor preference, which for these animals is their first test (Test). The groups differed according to how the waiting period was implemented. The larvae were either put in a Petri dish with an agarose substrate (left plots; this corresponds to the procedures used in Figures 1-3) or in a water droplet on a Petri dish lid (right plots). For either implementation of the waiting period, appetitive associative memory was revealed both by higher odor preferences in the paired than in the unpaired group $(A)$ and by significantly positive $\mathrm{PI}(B)$. Critically, a comparison of the PI scores revealed stronger memory when the animals were kept in the water droplet $(B)$. Sample sizes are given within the figure. * refers to MWU comparisons between groups, " refers to OSS comparisons to chance levels, that is, to zero $\left({ }^{*}{ }^{*} P<0.05\right.$ corrected according to Bonferroni-Holm). Other details as in Figures 1-3. 
A

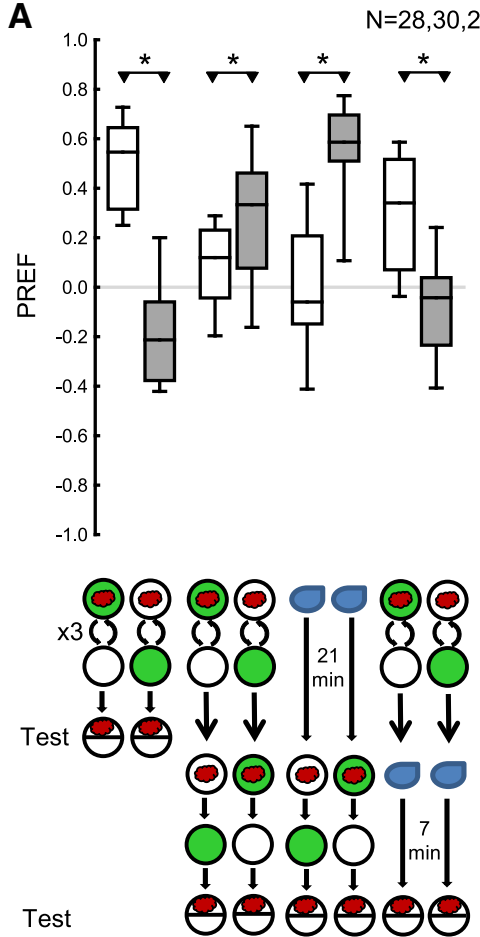

B

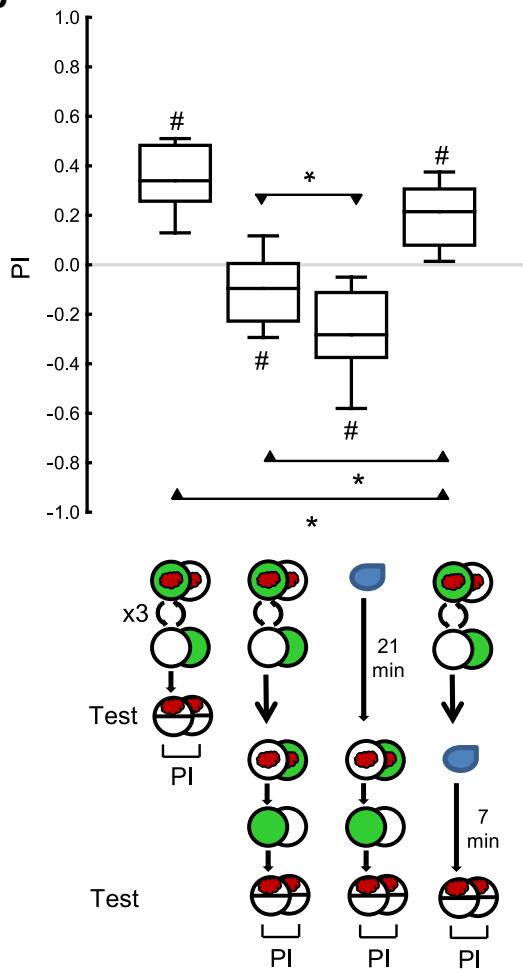

Figure 5. Absolute appetitive reversal learning paradigm in larval Drosophila. (A) The larvae were tested for their odor preference either (i) immediately after a one-phase training, (ii) after training with reversed contingencies in the first and the second training phase, (iii) after omitting the first training phase, or (iv) after omitting the second training phase. (B) Pls calculated from the preference scores in $A$. Positive and negative Pls indicate appetitive memory related to the first and the second training phase, respectively. The Pls after reversed-contingency training were less negative than when the first training phase was omitted, suggesting a persisting impact from the first training phase. In turn, after reversedcontingency training, the Pls were more negative than when the second training phase was omitted, suggesting behavior in accordance with the second training phase. The fact that the Pls after reversed-contingency training were significantly negative and that the PIs were significantly positive when the second training phase was omitted confirms these respective conclusions. Sample sizes are given within the figure. * refers to MWU comparisons between groups," refers to OSS comparisons to chance levels, that is, to zero $\left({ }^{*}, \# P<0.05\right.$ corrected according to Bonferroni-Holm). Other details as in Figures 1-4.
We next tested reversal learning using a differential, two-odor version of our paradigm. The same procedure as in Figure 5 was used except that 1-octanol (OCT, undiluted) was applied as the second odor (i.e., training was either $\mathrm{AM}+/ \mathrm{OCT}$ or AM/OCT+). Then, the larvae were tested for their choice between AM and OCT and the data were analyzed as detailed in the Materials and Methods section. In this two-odor, differential conditioning paradigm, too, the larvae showed reversal learning (Fig. 6A,B).

Together, these results demonstrate reversal learning of larval Drosophila in the appetitive domain.

\section{Aversive reversal learning in larval Drosophila}

Finally, we enquired into reversal learning in the aversive domain. As in the appetitive case, both absolute conditioning and differential conditioning paradigms were performed, this time using highly concentrated salt (sodium chloride, $\mathrm{NaCl}, 1.5 \mathrm{M}$ ) as the punishment (Gerber and Hendel 2006).

In the one-odor aversive paradigm (Fig. 7A,B), the larvae were trained as in Figure 5 except that (i) one rather than three training cycles was applied in the first training phase and (ii) the duration of the individual training trials and the duration of the test were 5 min each rather than 2.5 and 3 min, respectively. Also, (iii) rather than maintaining the larvae in a water droplet, fresh agarose Petri dishes with neither odor nor punishment were used for maintaining the larvae when omitting the first or the second training phase. In the case of salt as the punishment, these parameters seemed suitable in the light of Widmann et al. (2016). Further, (iv) the test was performed on salt-containing Petri dishes, as punishment memories in larvae are only behaviorally expressed as part of learned escape behavior, that is, if the presence of the punishment warrants escape (Gerber and Hendel 2006; Schleyer et al. 2011, 2015; Widmann et al. 2016).

For the two-odor aversive paradigm, the procedure was as described in the preceding paragraph, using $\mathrm{AM}$ as one of the odors (diluted 1:250 in paraffin oil) and benzaldehyde (BA, undiluted) as the second odor (Fig. 8A,B). Please note that according to the convention, aversive memory related to the first training phase is indicated by negative PI (Equation 2; Materials and Methods), whereas aversive memory for the second training phase is shown by positive PI (Equation 3; Materials and Methods)

For both absolute and differential conditioning, the PIs were more positive after reversed-contingency training than when the second training phase was omitted, suggesting behavior in accordance with the second training phase (Figs. 7B, 8B). This conclusion is confirmed by the observation that the PIs after reversed-contingency training were significantly positive (Figs. 7B, 8B). Memory for the first training phase is detectable as well, as shown by the significantly negative PI when the second training phase was omitted (Figs. 7B, 8B). However, the PIs are statistically indistinguishable after reversed-contingency training and when the first training phase is omitted, so the comparison of these conditions does not provide evidence for a behavioral effect of the memory for the first training phase (Figs. 7B, 8B). Of note, is that two independent replications of these two experimental conditions, in differential conditioning, do reveal a persisting impact of the first training phase (Fig. 9; Supplemental Fig. S3A,B). In any event, and as expected, increasing the number of training cycles in the first training phase outweighs the impact of the second training phase (Supplemental Fig. S3C,D).

Overall, these results demonstrate the reversal learning of larval Drosophila in the aversive domain as well.

\section{Discussion}

\section{Strategies for contingency adjustment}

Our results demonstrate reversal learning in larval Drosophila. After first associating an odor with the presence or the absence of a 
A

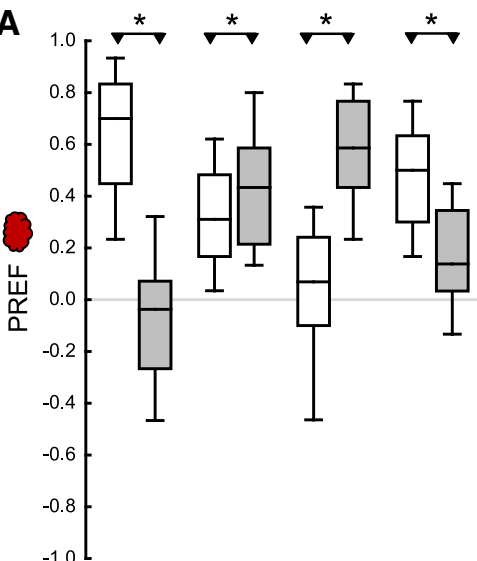

\section{$\mathrm{N}=49$}

each

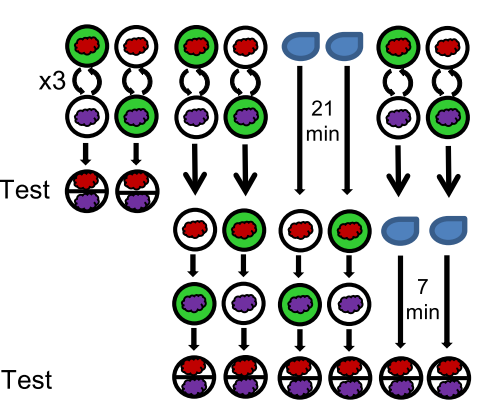

B

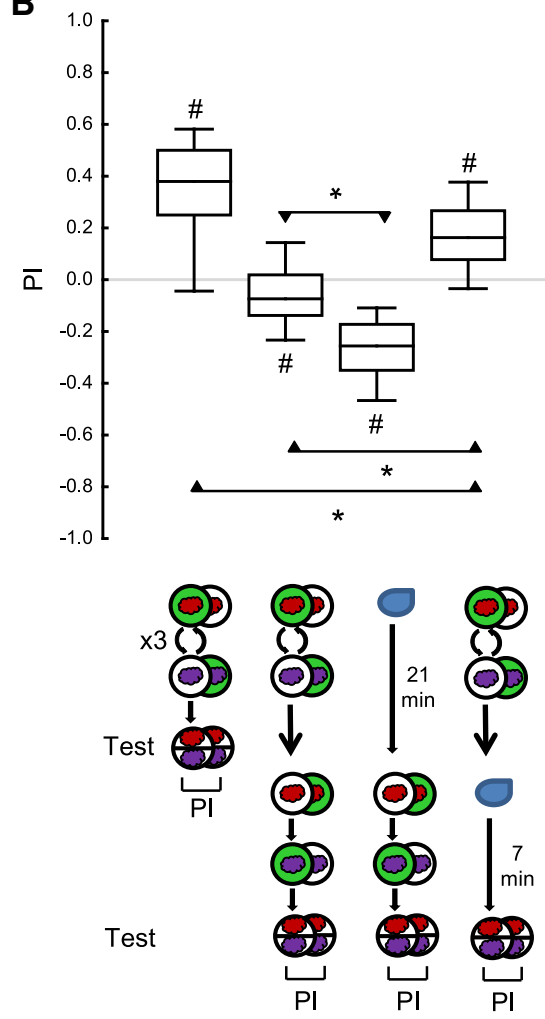

Figure 6. Differential appetitive reversal learning paradigm in larval Drosophila. The larvae were trained and tested as in Figure 5, except that 1-octanol was used as the second odor (violet cloud) in all training trials in which $n$-amyl acetate (red cloud) was not presented. (A) The larvae were tested either (i) immediately after one-phase training, (ii) after training with reversed contingencies in the first and the second training phase, (iii) after omitting the first training phase, or (iv) after omitting the second training phase. Preference scores (PREF) reflect preference for $n$-amyl acetate (red cloud). (B) $\mathrm{Pl}$ calculated from the preference scores in $A$. Positive and negative Pls indicate appetitive memory related to the first and the second training phase, respectively. The Pls after reversedcontingency training were less negative than when the first training phase was omitted, suggesting a persisting impact from the first training phase. In turn, after reversed-contingency training, the Pls were more negative than when the second training phase was omitted, suggesting behavior in accordance with the second training phase. The fact that the Pl after reversed-contingency training were significantly negative and that the PIs were significantly positive when the second training phase was omitted confirms these respective conclusions. Sample sizes are given within the figure. * refers to MWU comparisons between groups, " refers to OSS comparisons to chance levels, that is, to zero (*,\# $P<0.05$ corrected according to Bonferroni-Holm). Other details as in Figures 1-5.

with relatively intense training for the initial association ( 3 cycles) and relatively little training for the second (1 cycle). This is in contrast with results, for example, in the honeybee, where appetitive reversal learning paradigms include several reversed-contingency training trials and often use a 1:1 ratio of trial numbers in the first and the second training phase (Ben-Shahar et al. 2000; Komischke et al. 2002; Hadar and Menzel 2010; Mota and Giurfa 2010; Boitard et al. 2015; Cabirol et al. 2018). Specifically, during the second phase, bees typically persist in responding to the cue that was originally reinforced, meaning that the effects of training from the first phase persist and need to be overcome during the second, reversed-contingency training phase (Hadar and Menzel 2010; Mota and Giurfa 2010). This might indicate two different cognitive strategies which can both bring about contingency adjustment: during reversed-contingency training, bees might take advantage of a higher mnemonic capacity and be able to maintain memory for the initial association more easily despite the conflicting memories to be established during the reversal phase. Such a strategy would come at the cost of relatively slow and incomplete contingency adjustment. In contrast, the larvae might more easily discard old and establish new memories for the sake of quick contingency adjustment, coming at the cost of only having a narrow temporal window for their mnemonic record, consistent with the relatively quick memory decay in these animals (Neuser et al. 2005; Kleber et al. 2016; Weiglein et al. 2019). Conceivably, this is adaptive for bees because the initial contingencies might reemerge during their relatively long lives as foragers, whereas larvae might have already pupariated before this is the case. reinforcer (i.e., reward or punishment), the animals adapted their behavior to the reversal of these contingencies. We regard this as "true" reversal learning because after reversed-contingency training the effects of both the first and the second training phase remain behaviorally detectable (Figs. 5-8). Notably, the present data do not reveal whether this comes about by individual animals having distinct, opposing associative memories for the two training phases, or whether subsets of animals have such memories for only one or the other of the training phases, or whether all animals operate using a trial-by-trial update of their experiences. Recent data on the spatially segregated coexistence of opposing physiological memory traces in adult flies, specifically the coexistence of an acquisition-memory trace and an extinction-memory trace for one and the same odor (Felsenberg et al. 2018), are consistent with the first scenario.

Nonetheless, at least for the appetitive domain, the extinction/decay of memory appears to be rather rapid in larvae and fittingly we observe "true" reversal learning only in a paradigm

\section{Generality of reversal learning across valence domains}

We found reversal learning in both the appetitive domain (Figs. 5, 6) and the aversive domain (Figs. 7-9), corresponding to what has been reported for adult flies (Tully and Quinn 1985; Tully et al. 1990; Ren et al. 2012; Wu et al. 2012; Chouhan et al. 2015), bees (Giurfa 2003; Mota and Giurfa 2010; Pérez Claudio et al. 2018), and vertebrates (Rajalakshmi and Jeeves 1965; O'Malley and Bruning 1969; Morris and Dolan 2004; Bissonette et al. 2008; Costa et al. 2015; Izquierdo et al. 2017; Atlas and Phelps 2018). This suggests reversal learning as a general faculty widespread in the animal kingdom, even where the nervous system is numerically as simple as is the case for the larva with its $\sim 10,000$ neurons (Dumstrei et al. 2003; Nassif et al. 2003).

We note that for the present experiments quantitative comparisons of the ease of reversal learning across valence domains are not informative. The reason is that our initial experiments suggested that different experimental parameters need to be chosen to 
A
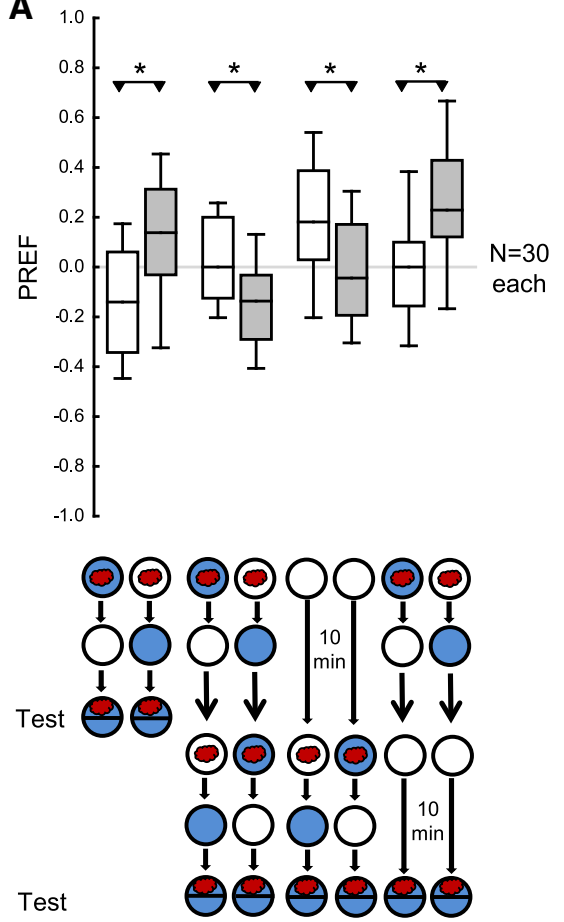

B

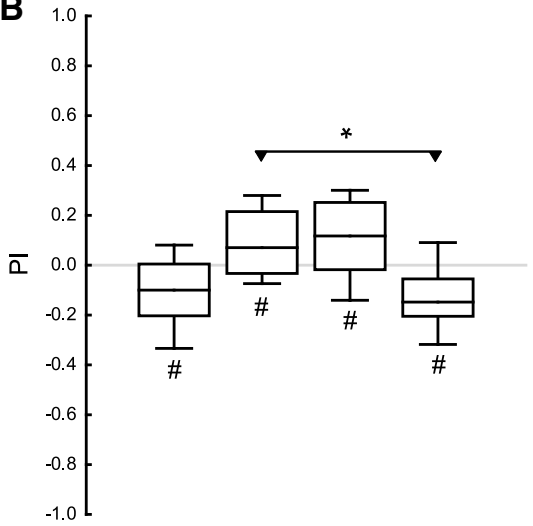

Test

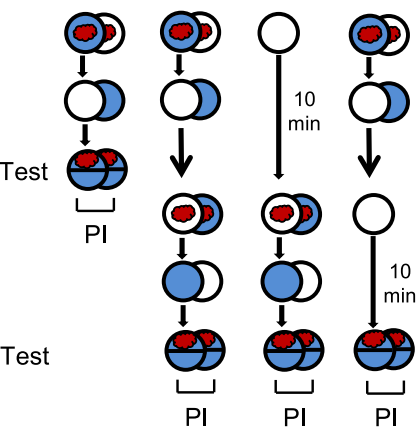

Figure 7. Absolute aversive reversal learning paradigm in larval Drosophila. The larvae were trained as in Figure 5 with modifications for measuring reversal learning in the aversive domain. Specifically, (i) a high concentration of salt (sodium chloride) was used as the punishment (blue fill of Petri dish); (ii) only one cycle of training was given in the first training phase; (iii) the duration of individual training trials and the duration of the test were $5 \mathrm{~min}$ each; (iv) agarose Petri dishes with neither odor nor punishment were used for maintaining the larvae when omitting the first or the second training phase; and (v) the test was performed on salt-containing Petri dishes. $(A)$ The larvae were tested either (i) immediately after onephase training, (ii) after training with reversed contingencies in the first and the second training phase, (iii) after omitting the first training phase, or (iv) after omitting the second training phase. (B) Pls calculated from the preference scores in $A$. Negative and positive Pls indicate aversive memory related to the first and the second training phase, respectively. The PIs after reversed-contingency training were more positive than when the second training phase was omitted, suggesting behavior in accordance with the second training phase. In addition, the $\mathrm{PI}$ after reversed-contingency training were significantly positive, confirming this conclusion. The fact that the Pls were significantly negative when the second training phase was omitted suggests behavior in accordance with the first training phase. However, the PIs were no less positive after reversed-contingency training than when the first training phase was omitted, offering no evidence for a behavioral effect of the memory for the first training phase. Sample sizes are given within the figure. * refers to MWU comparisons between groups, " refers to OSS comparisons to chance levels, that is, to zero ( ${ }^{*, \# ~} P<0.05$ corrected according to Bonferroni-Holm). Other details as in Figures 1-6.

detect reversal learning in the appetitive and the aversive case. Procedural differences include the number of cycles in the first training phase ( 1 cycle versus 3 cycles), the duration of individual training trials ( $2.5 \mathrm{~min}$ versus $5 \mathrm{~min}$ ), test duration ( $3 \mathrm{~min}$ versus $5 \mathrm{~min}$ ), the identity of the second odor for differential conditioning (OCT versus BA) and the circumstances in which the animals are maintained when omitting either the first or the second training phase (water droplet versus pure agarose Petri dish). Bearing these caveats in mind, we note that, as previously reported (Widmann et al. 2016), aversive memories appear more stable over time than appetitive ones (compare the respective leftmost and rightmost plots in Figs. 5B, 6B to the corresponding results in Figs. 7B, 8B).

\section{Utility of a larval reversal learning paradigm}

The availability of a reversal paradigm enriches the behavioral toolbox for studying associative learning in the larva. As argued by
Thum and Gerber (2019), such an extension is important because the newly discovered synaptic connections in the mushroom bodies (Eichler et al. 2017; Takemura et al. 2017), the brain center for associative learning in insects, now call for functional interpretation. Indeed, these connections suggest a richer mnemonic functionality than previously acknowledged on the basis of the typically rather simple tasks used to investigate them (Heisenberg 1998, 2003; Menzel and Giurfa 2001). In this context, the present reversal learning paradigm might become useful (for pioneering work on the cellular basis of reversal learning in adult flies: Ren et al. 2012; Wu et al. 2012; for related work in bees: Devaud et al. 2007; Boitard et al. 2015; Cabirol et al. 2018). In addition, the possible coexistence of (i) memory extinction/decay with (ii) memory for the first training phase, and (iii) memory for the second training phase might imply a complexity of memory "content" that also defines critical demands for computational models of adaptive behavior in these animals (for a recent circuit-level analysis of extinction memory in adults: Felsenberg et al. 2018)

In psychological terms, reversal learning may serve as an indicator of cognitive flexibility when an animal is confronted with environmental variations (Izquierdo et al. 2017). Such a measure could be useful for seeing what the full range of effects of drugs affecting memory is (Michels et al. 2018), or for delineating the scope of mutant phenotypes.

\section{Materials and Methods}

\section{Flies and materials}

Fruit flies D. melanogaster of the Canton-S wild-type strain were kept in mass culture, maintained at $25^{\circ} \mathrm{C}, 60 \%-70 \%$ humidity, and a 12/12 h light/dark cycle.

We used stage 3 larvae aged $5 \mathrm{~d}(120$ h) after egg laying. Petri dishes of $85 \mathrm{~mm}$ inner diameter (Sarstedt) were used, filled either with 1\% agarose only (CAS: 9012-36-6; Roth) or with $1 \%$ agarose with fructose added ( $99 \%$ purity; $2 \mathrm{M}$; CAS: $57-48-7$; Roth) as the reward or with $2.5 \%$ agarose with sodium chloride added (99.9\% purity; $1.5 \mathrm{M}$; CAS: 7647-14-5; Sigma-Aldrich) as the punishment. Once solidified, the dishes were covered with their lids and left at $4^{\circ} \mathrm{C}$ until the experiment started, and for a maximum of $2 \mathrm{wk}$.

As the odor, we used $n$-amyl acetate (AM, CAS: 628-63-7; Merck) diluted 1:20 or 1:250 (the latter only for differential, two-odor aversive learning) in paraffin oil (CAS: 8042-47-5; AppliChem), 1-octanol (OCT, undiluted, CAS: 111-87-5; Sigma-Aldrich), and benzaldehyde (BA, undiluted; CAS: 100-527; Sigma-Aldrich). Paraffin oil is without behavioral effect as an odor (Saumweber et al. 2011). Before experiments, $10 \mu \mathrm{L}$ of the respective odor was added to custom-made odor containers made of Teflon ( $5 \mathrm{~mm}$ inner diameter) covered by perforated lids (5-10 holes of $0.5 \mathrm{~mm}$ diameter each). All experiments were performed under a fume hood, at $\sim 23^{\circ} \mathrm{C}-25^{\circ} \mathrm{C}$. 
A
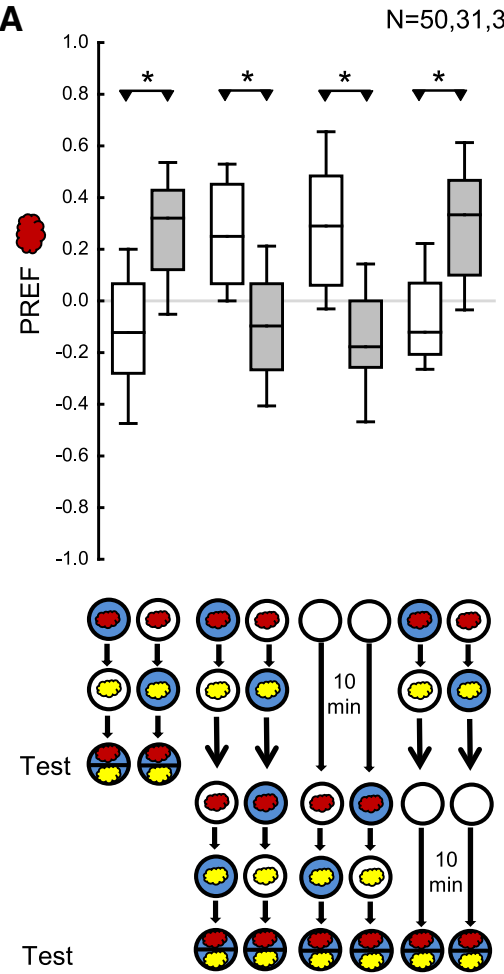

B

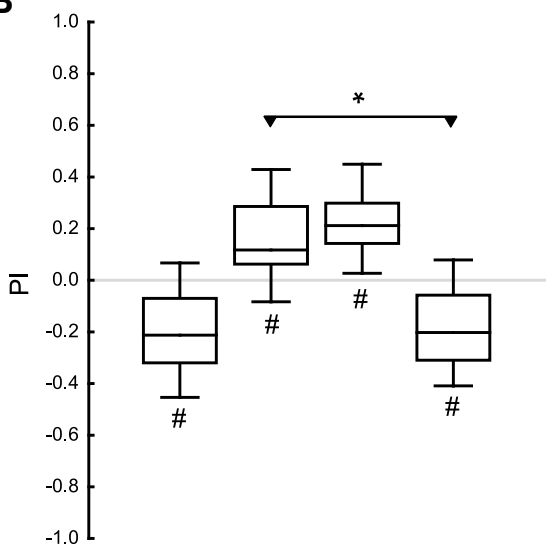

Figure 8. Differential aversive reversal learning paradigm in larval Drosophila. The larvae were trained and tested as in Figure 7 , except that BA was used as the second odor (yellow cloud) in all training trials in which $n$-amyl acetate (red cloud) was not presented. (A) The larvae were tested either (i) immediately after one-phase training, (ii) after training with reversed contingencies in the first and the second training phase, (iii) after omitting the first training phase, or (iv) after omitting the second training phase. Preference scores (PREF) reflect preference for $n$-amyl acetate (red cloud). (B) Pls calculated from the preference scores in $A$. Negative and positive Pls indicate aversive memory related to the first and the second training phase, respectively. The Pls after reversed-contingency training were more positive than when the second training phase was omitted, suggesting behavior in accordance with the second training phase. In addition, the Pls after reversed-contingency training were significantly positive, confirming this conclusion. The fact that the PI were significantly negative when the second training phase was omitted suggests behavior in accordance with the first training phase. However, the Pls are no less positive after reversed-contingency training than when the first training phase is omitted, offering no evidence for a behavioral effect of the memory for the first training phase (see also Fig. 9). Sample sizes are given within the figure. * refers to MWU comparisons between groups, " refers to OSS comparisons to chance levels, that is, to zero $(*, \# P<0.05$ corrected according to Bonferroni-Holm). Other details as in Figures 1-7.
A
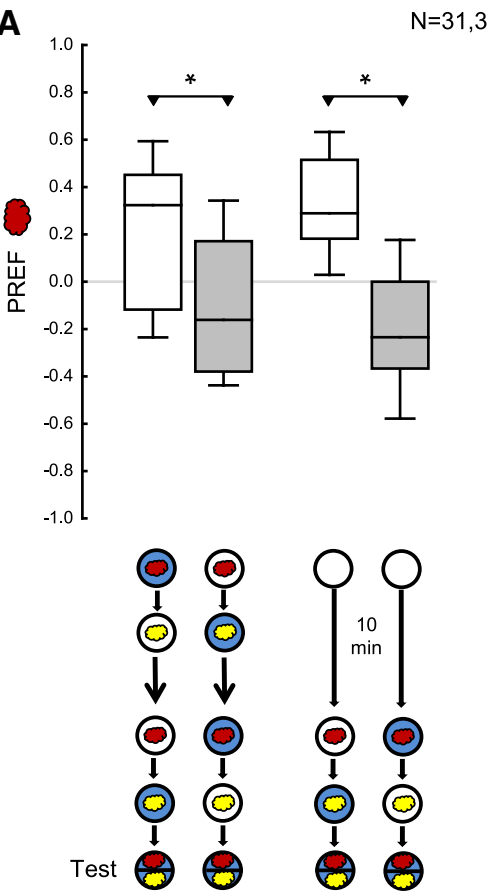

B
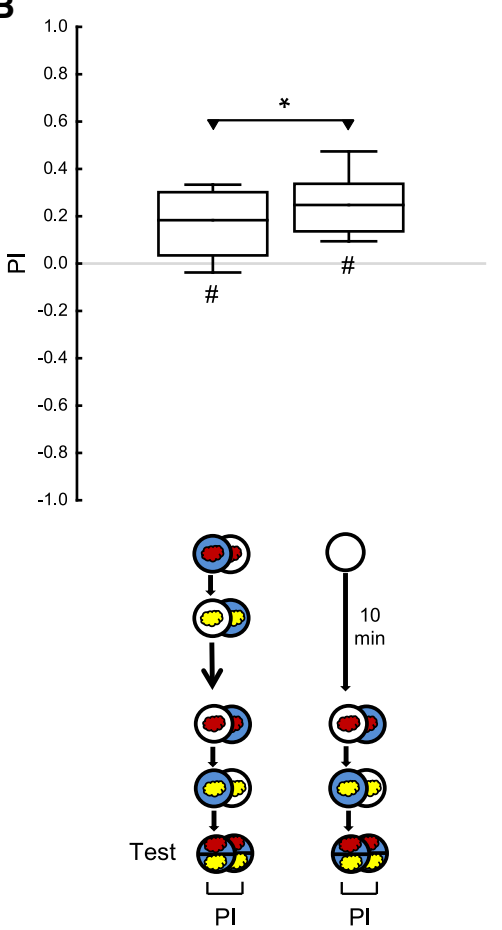

Figure 9. Influence of the first training phase in the differential aversive reversal learning paradigm, revisited. (A) Repetition of two experimental conditions from Figure 8 . The larvae were tested after training with reversed contingencies in the first and the second training phase, or after omitting the first training phase. Preference scores (PREF) reflect preference for $n$-amyl acetate (red cloud). (B) Pls calculated from the preference scores in A. Positive Pls indicate aversive memory related to the second training phase. The Pls after reversed-contingency training were less positive than when the first training phase was omitted, suggesting a small yet significant persisting impact from the first training phase. Sample sizes are given within the figure. * refers to MWU comparisons between groups, \# refers to OSS comparisons to chance levels, that is, to zero (*,\# $P<0.05$ corrected according to Bonferroni-Holm). Other details as in Figures 1-8. 


\section{Behavioral experiments}

The reversal learning procedure is described as follows (Fig. 1A). Whenever changed versions of the standard procedure are used, this is mentioned in the respective part of the Results section.

The reversal learning procedure consisted of a first training phase, followed by a first test, and a subsequent second training phase followed by a second test. In both training phases, a standard two-group reciprocal conditioning paradigm was used (Scherer et al. 2003; Neuser et al. 2005; Gerber and Hendel 2006; Saumweber et al. 2011; Michels et al. 2017). In one of the groups, the larvae were trained such that the odor was paired with the reward, whereas the other group received unpaired training, that is, separate presentations of odor-alone and reward-alone. To equate the groups for handling, the total number of training events, and the total duration of the training, a blank was introduced for the paired group during which no reward and two empty odor containers (EM) were presented. After such reciprocal training (AM+/EM in the paired group and $\mathrm{AM} / \mathrm{EM}+$ in the unpaired group), the preference for the odor was assessed in a first test. During the second training phase, the procedure was the same except that the contingencies between the odor and the reward were reversed and two cycles of the above-mentioned training were given. The experiment concluded with a second test for odor preferences in both groups.

Specifically, before starting an experiment, a cohort of 30 larvae was collected from a food vial and briefly washed in tap water. During paired training $(\mathrm{AM}+/ \mathrm{EM})$, the larvae were placed by using a wet, soft brush in the middle of a Petri dish with fructose added, in the presence of two containers filled with AM. Then, the lid was closed and the larvae were allowed to move freely for $2.5 \mathrm{~min}$. The larvae were then removed and placed on a fresh, pure agarose Petri dish in the presence of two empty containers, the lid was closed, and the larvae could again move freely for $2.5 \mathrm{~min}$. This cycle was performed once. The sequence of training events within a cycle was alternated across repetitions of the experiments, that is, for half of the cases we started with $\mathrm{AM}+$, and for the other half with EM. After this training phase, the larvae were tested for their odor preference (Test 1). During the test, the larvae were placed in the center of a fresh, pure agarose Petri dish containing one AM container on one side, and one EM container on the other side, and the lid was closed. After $3 \mathrm{~min}$, the number of larvae on the AM side (\#AM), the EM side (\#EM), as well as in the neutral middle zone $(10 \mathrm{~mm})$ was counted and olfactory preference (PREF) was calculated as

$$
\mathrm{PREF}=\frac{(\# \mathrm{AM}-\# \mathrm{EM})}{\# \text { Total }}
$$

Larvae that had moved onto the lid or onto the odor containers during the test (typically $<5 \%$ ) were discarded from the analysis.

For the unpaired case (AM/EM+), the procedure was the same except that the odor and the reward were presented separately to the animals. The larvae were placed onto a pure agarose Petri dish in the presence of AM. Then, they were transferred to an agarose Petri dish with fructose added, together with EM. The larvae were then tested for their odor preference (Test 1) and the olfactory preference score was calculated according to Equation (1).

Appetitive associative memory is indicated by a relatively higher preference for $\mathrm{AM}$ after $\mathrm{AM}+/ \mathrm{EM}$ training in the first training phase compared with the reciprocal $\mathrm{AM} / \mathrm{EM}+$ training during that phase. These differences in AM preference were quantified by the associative performance index (PI):

$$
\mathrm{PI}=\frac{\left(\mathrm{PREF}_{\text {Paired in phase 1 }}-\mathrm{PREF}_{\text {Unpaired in phase } 1}\right)}{2}
$$

Thus, positive PI values indicate appetitive associative memory related to the first training phase, whereas negative PI values would indicate aversive associative memory related to it.

After this first test for their odor preference, both groups of larvae were transferred to a subsequent second training phase, using the same procedure as for the first training phase, except that the contingencies between the odor and the reward were reversed. In other words, the group that had initially received paired training was now trained by two cycles of unpaired presentations of odor and reward (Phase 1: AM+/EM; Phase 2: AM/EM+) (please note that an extinction procedure would involve the presentation of only the odor, but not the reward), and the group initially trained unpaired now received two cycles of paired training (Phase 1: AM/ $\mathrm{EM}+$; Phase 2: $\mathrm{AM}+/ \mathrm{EM})$. Then, a second test (Test 2) was performed and the olfactory preference score was calculated according to Equation (1). The associative performance index (PI) was calculated as

$$
\mathrm{PI}=\frac{\left(\mathrm{PREF}_{\text {Unpaired in phase 2 }}-\mathrm{PREF}_{\text {Paired in phase 2 }}\right)}{2}
$$

Thus, appetitive associative memory related to the second training phase is indicated by negative PI values, whereas positive PI values would indicate aversive associative memory related to it.

Note that, whenever the second training phase was omitted, PI values were calculated according to Equation (2); whenever the first training phase was omitted, PI values were calculated according to Equation (3).

\section{Statistics}

Nonparametric statistical tests were applied throughout. For comparisons to chance levels (i.e., to zero) one-sample sign tests (OSS) were used. For between-group comparisons, Kruskal-Wallis tests (KW) and Mann-Whitney $U$-tests (MWU) were used for multiple and two-group comparisons, respectively. For within-group comparisons, Wilcoxon matched-pairs tests were used. The Bonferroni-Holm correction was applied to maintain an error rate below 5\%. Statistical analyses were performed with Statistica 12 (StatSoft) and R (R Developmental Core Team 2008). Data were displayed as box plots, the middle line showing the median, the box boundaries the $25 \%$ and $75 \%$ quantiles, and the whiskers the $10 \%$ and $90 \%$ quantiles.

\section{Competing interest statement}

The authors declare no competing interests.

\section{Acknowledgments}

This study received institutional support from the Otto von Guericke University Magdeburg (OvGU), the Wissenschaftsgemeinschaft Gottfried Wilhelm Leibniz (WGL), the Leibniz Institute for Neurobiology (LIN), as well as grant support from the Deutsche Forschungsgemeinschaft (DFG-GE 1091/4-1, CRC 779 Motivated behavior, and FOR 2705 Mushroom body to B.G.; DFG-TH 1584/ 3-1 to A.S.T.). N.M., M.S., A.S.T., and B.G. conceived and designed the experiments; N.M., S.H., J.W., A.W., and D.W. performed them; N.M. performed statistical analyses; N.M. and B.G. wrote the manuscript with input from all authors. We thank K. Wulfinghoff (OvGU) and W. Näser (OvGU) for their experimental contributions, B. Kracht (LIN), H. Reim (LIN), T. Niewalda (LIN), and H. Wickborn (LIN) for their technical assistance, and R.D.V. Glasgow (Zaragoza, Spain) for language editing.

\section{References}

Almeida-Carvalho MJ, Berh D, Braun A, Chen Y-C, Eichler K, Eschbach C, Fritsch PM, Gerber B, Hoyer N, Jiang X, et al. 2017. The $\mathrm{Ol}_{1}$ mpiad: concordance of behavioural faculties of stage 1 and stage 3 Drosophila larvae. J Exp Biol 220: 2452-2475. doi:10.1242/jeb.156646

Atlas LY, Phelps EA. 2018. Prepared stimuli enhance aversive learning without weakening the impact of verbal instructions. Learn Mem 25: 100-104. doi:10.1101/lm.046359.117

Ben-Shahar Y, Thompson CK, Hartz SM, Smith BH, Robinson GE. 2000. Differences in performance on a reversal learning test and division of labor in honey bee colonies. Anim Cogn 3: 119-125. doi:10.1007/ s100710000068 
Bissonette GB, Martins GJ, Franz TM, Harper ES, Schoenbaum G, Powell EM 2008. Double dissociation of the effects of medial and orbital prefrontal cortical lesions on attentional and affective shifts in mice. J Neurosci 28: 11124-11130. doi:10.1523/JNEUROSCI.2820-08.2008

Boitard C, Devaud J-M, Isabel G, Giurfa M. 2015. GABAergic feedback signaling into the calyces of the mushroom bodies enables olfactory reversal learning in honey bees. Front Behav Neurosci 9: 198. doi:10 $.3389 /$ fnbeh.2015.00198

Brigman JL, Graybeal C, Holmes A. 2010. Predictably irrational: assaying cognitive inflexibility in mouse models of schizophrenia. Front Neurosci 4: 13 . doi:10.3389/neuro.01.013.2010

Cabirol A, Cope AJ, Barron AB, Devaud J-M. 2018. Relationship between brain plasticity, learning and foraging performance in honey bees. PLoS One 13: e0196749. doi:10.1371/journal.pone.0196749

Chouhan NS, Wolf R, Helfrich-Förster C, Heisenberg M. 2015. Flies remember the time of day. Curr Biol 25: 1619-1624. doi:10.1016/j.cub 2015.04.032

Clark MQ, Zarin AA, Carreira-Rosario A, Doe CQ. 2018. Neural circuits driving larval locomotion in Drosophila. Neural Dev 13: 6. doi:10.1186/ s13064-018-0103-z

Cobb M, Scott K, Pankratz M. 2008. Gustation in Drosophila melanogaster. SEB Exp Biol Ser 63: 1-38.

Costa VD, Tran VL, Turchi J, Averbeck BB. 2015. Reversal learning and dopamine: a Bayesian perspective. J Neurosci 35: 2407-2416. doi:10 $.1523 /$ JNEUROSCI.1989-14.2015

Devaud JM, Blunk A, Podufall J, Giurfa M, Grünewald B. 2007. Using local anaesthetics to block neuronal activity and map specific learning tasks to the mushroom bodies of an insect brain. Eur J Neurosci 26: 3193 3206.

Diegelmann S, Klagges B, Michels B, Schleyer M, Gerber B. 2013. Maggot learning and Synapsin function. J Exp Biol 216: 939-951. doi:10.1242/ jeb.076208

Dumstrei K, Wang F, Nassif C, Hartenstein V. 2003. Early development of the Drosophila brain: V. Pattern of postembryonic neuronal lineages expressing DE-cadherin. J Compar Neurol 455: 451-462. doi:10.1002/ cne.10484

Eichler K, Li F, Litwin-Kumar A, Park Y, Andrade I, Schneider-Mizell CM, Saumweber T, Huser A, Eschbach C, Gerber B, et al. 2017. The complete connectome of a learning and memory centre in an insect brain. Nature 548: $175-182$. doi:10.1038/nature23455

Felsenberg J, Jacob PF, Walker T, Barnstedt O, Edmondson-Stait AJ, Pleijzier MW, Otto N, Schlegel P, Sharifi N, Perisse E, et al. 2018. Integration of parallel opposing memories underlies memory extinction. Cell 175: 709-722.e715. doi:10.1016/j.cell.2018.08.021

Gerber B, Hendel T. 2006. Outcome expectations drive learned behaviour in larval Drosophila. Proc Biol Sci 273: 2965-2968. doi:10.1098/rspb.2006 .3673

Giurfa M. 2003. Cognitive neuroethology: dissecting non-elemental learning in a honeybee brain. Curr Opin Neurobiol 13: 726-735. doi:10 .1016/i.conb.2003.10.015

Gomez-Marin A, Louis M. 2012. Active sensation during orientation behavior in the Drosophila larva: more sense than luck. Curr Opin Neurobiol 22: 208-215. doi:10.1016/j.conb.2011.11.008

Gruner P, Pittenger C. 2017. Cognitive inflexibility in obsessive-compulsive disorder. Neuroscience 345: 243-255. doi:10.1016/j.neuroscience.2016 .07 .030

Hadar R, Menzel R. 2010. Memory formation in reversal learning of the honeybee. Front Behav Neurosci 4: 186. doi:10.3389/fnbeh.2010 .00186

Heisenberg M. 1998. What do the mushroom bodies do for the insect brain? An introduction. Learn Mem 5: 1-10.

Heisenberg M. 2003. Mushroom body memoir: from maps to models. Nat Rev Neurosci 4: 266-275. doi:10.1038/nrn1074

Helfrich-Förster C. 2004. The circadian clock in the brain: a structural and functional comparison between mammals and insects. J Comp Physiol A 190: 601-613. doi:10.1007/s00359-004-0527-2

Izquierdo A, Jentsch JD. 2012. Reversal learning as a measure of impulsive and compulsive behavior in addictions. Psychopharmacology (Berl) 219: 607-620. doi:10.1007/s00213-011-2579-7

Izquierdo A, Brigman JL, Radke AK, Rudebeck PH, Holmes A. 2017. The neural basis of reversal learning: an updated perspective. Neuroscience 345: 12-26. doi:10.1016/j.neuroscience.2016.03.021

Jacobson AL. 1963. Learning in flatworms and annelids. Psychol Bull 60: 74. doi:10.1037/h0046468

Kaplan F, Oudeyer P-Y. 2007. In search of the neural circuits of intrinsic motivation. Front Neurosci 1: 225-236. doi:10.3389/neuro.01.1.1.017 .2007

Kleber J, Chen Y-C, Michels B, Saumweber T, Schleyer M, Kähne T, Buchner E, Gerber B. 2016. Synapsin is required to "boost" memory strength for highly salient events. Learn Mem 23: 9-20. doi:10.1101/lm .039685 .115
Kohsaka H, Guertin PA, Nose A. 2017. Neural circuits underlying fly larval locomotion. Curr Pharm Des 23: 1722-1733. doi:10.2174/ 1381612822666161208120835

Komischke B, Giurfa M, Lachnit H, Malun D. 2002. Successive olfactory reversal learning in honeybees. Learn Mem 9: 122-129. doi:10.1101/lm .44602

Marvin CB, Shohamy D. 2016. Curiosity and reward: valence predicts choice and information prediction errors enhance learning. J Exp Psychol Gen 145: $266-272$. doi: $10.1037 / \mathrm{xge} 0000140$

Mayford M, Kandel ER. 1999. Genetic approaches to memory storage. Trends Genet 15: 463-470. doi:10.1016/S0168-9525(99)01846-6

Menzel R, Giurfa M. 2001. Cognitive architecture of a mini-brain: the honeybee. Trends Cogn Sci 5: 62-71. doi:10.1016/S1364-6613(00) 01601-6

Michels B, Saumweber T, Biernacki R, Thum J, Glasgow RDV, Schleyer M, Chen Y-C, Eschbach C, Stocker RF, Toshima N, et al. 2017. Pavlovian conditioning of larval Drosophila: an illustrated, multilingual, hands-on manual for odor-taste associative learning in maggots. Front Behav Neurosci 11: 45 . doi:10.3389/fnbeh.2017.00045

Michels B, Zwaka H, Bartels R, Lushchak O, Franke K, Endres T, Fendt M, Song I, Bakr M, Budragchaa T, et al. 2018. Memory enhancement by ferulic acid ester across species. Sci Adv 4: eaat6994. doi:10.1126/sciadv .aat6994

Morris J, Dolan RJ. 2004. Dissociable amygdala and orbitofrontal responses during reversal fear conditioning. Neuroimage 22: $372-380$. doi:10 $.1016 / j$.neuroimage.2004.01.012

Mota T, Giurfa M. 2010. Multiple reversal olfactory learning in honeybees. Front Behav Neurosci 4: 48. doi:10.3389/fnbeh.2010.00048

Nassif C, Noveen A, Hartenstein V. 2003. Early development of the Drosophila brain: III. The pattern of neuropile founder tracts during the larval period. J Comp Neurol 455: 417-434. doi:10.1002/cne .10482

Neuser K, Husse J, Stock P, Gerber B. 2005. Appetitive olfactory learning in Drosophila larvae: effects of repetition, reward strength, age, gender, assay type and memory span. Anim Behav 69: 891-898. doi:10.1016/j anbehav.2004.06.013

O'Malley JJ, Bruning JL. 1969. Aversive stimulation and reversal learning. Psychon Sci 15: 40. doi:10.3758/BF03336187

Pavlov IP. 1927. Conditioned reflexes: an investigation of the physiological activity of the cerebral cortex. Oxford University Press, London.

Pérez Claudio E, Rodriguez-Cruz Y, Arslan OC, Giray T, Agosto Rivera JL, Kence M, Wells H, Abramson CI. 2018. Appetitive reversal learning differences of two honey bee subspecies with different foraging behaviors. PeerJ 6: e5918. doi:10.7717/peerj.5918

Rajalakshmi R, Jeeves M. 1965. The relative difficulty of reversal learning (reversal index) as a basis of behavioural comparisons. Anim Behav 13: 203-211. doi:10.1016/0003-3472(65)90035-7

R Development Core Team. 2008. R: a language and environment for statistical computing. R Foundation for Statistical Computing, Vienna, Austria.

Reaume CJ, Sokolowski MB. 2011. Conservation of gene function in behaviour. Philos Trans R Soc B Biol Sci 366: 2100-2110. doi:10.1098/rstb .2011 .0028

Ren Q, Li H, Wu Y, Ren J, Guo A. 2012. A GABAergic inhibitory neural circuit regulates visual reversal learning in Drosophila. J Neurosci 32: 1152411538. doi:10.1523/JNEUROSCI.0827-12.2012

Rohwedder A, Wenz NL, Stehle B, Huser A, Yamagata N, Zlatic M, Truman JW, Tanimoto H, Saumweber T, Gerber B, et al. 2016. Four individually identified paired dopamine neurons signal reward in larval Drosophila. Curr Biol 26: 661-669. doi:10.1016/j.cub.2016.01 .012

Saumweber T, Husse J, Gerber B. 2011. Innate attractiveness and associative learnability of odors can be dissociated in larval Drosophila. Chem Senses 36: 223-235. doi:10.1093/chemse/bjq128

Saumweber T, Rohwedder A, Schleyer M, Eichler K, Chen Y, Aso Y, Cardona A, Eschbach C, Kobler O, Voigt A, et al. 2018. Functional architecture of reward learning in mushroom body extrinsic neurons of larval Drosophila. Nat Commun 9: 1104. doi:10.1038/ s41467-018-03130-1

Scherer S, Stocker RF, Gerber B. 2003. Olfactory learning in individually assayed Drosophila larvae. Learn Mem 10: 217-225. doi:10.1101/lm .57903

Schleyer M, Saumweber T, Nahrendorf W, Fischer B, von Alpen D, Pauls D, Thum A, Gerber B. 2011. A behavior-based circuit model of how outcome expectations organize learned behavior in larval Drosophila. Learn Mem 18: 639-653. doi:10.1101/lm.2163411

Schleyer M, Miura D, Tanimura T, Gerber B. 2015. Learning the specific quality of taste reinforcement in larval Drosophila. Elife 4: e04711. doi:10 $.7554 /$ eLife.04711

Schleyer M, Fendt M, Schuller S, Gerber B. 2018. Associative learning of stimuli paired and unpaired with reinforcement: evaluating evidence 
from maggots, flies, bees and rats. Front Psychol 9: 1494. doi:10.3389/ fpsyg.2018.01494

Stalnaker TA, Takahashi Y, Roesch MR, Schoenbaum G. 2009.

Neural substrates of cognitive inflexibility after chronic cocaine exposure. Neuropharmacology 56: 63-72. doi:10.1016/j.neuropharm .2008 .07 .019

Takemura S-Y, Aso Y, Hige T, Wong A, Lu Z, Xu CS, Rivlin PK, Hess H, Zhao T, Parag T, et al. 2017. A connectome of a learning and memory center in the adult Drosophila brain. Elife 6: e26975. doi:10.7554/eLife .26975

Thum AS, Gerber B. 2019. Connectomics and function of a memory network: the mushroom body of larval Drosophila. Curr Opin Neurobiol 54: 146-154. doi:10.1016/j.conb.2018.10.007

Tully T, Quinn WG. 1985. Classical conditioning and retention in normal and mutant Drosophila melanogaster. J Comp Physiol A 157: 263-277. doi:10.1007/BF01350033

Tully T, Boynton S, Brandes C, Dura J, Mihalek R, Preat T, Villella A. 1990 Genetic dissection of memory formation in Drosophila melanogaster. Cold Spring Harb Symp Quant Biol 55: 203-211. doi:10.1101/SQB.1990 .055 .01 .022
Weiglein A, Gerstner F, Mancini N, Schleyer M, Gerber B. 2019. One-trial learning in larval Drosophila. Learn Mem 26: 109-120. doi:10.1101/lm .049106 .118

Widmann A, Artinger M, Biesinger L, Boepple K, Peters C, Schlechter J, Selcho M, Thum AS. 2016. Genetic dissection of aversive associative olfactory learning and memory in Drosophila larvae. PLoS Genet 12: e1006378. doi:10.1371/journal.pgen.1006378

Widmann A, Eichler K, Selcho M, Thum AS, Pauls D. 2018. Odor-taste learning in Drosophila larvae. J Insect Physiol 106: 47-54. doi:10.1016/j .jinsphys.2017.08.004

Wu Y, Ren Q, Li H, Guo A. 2012. The GABAergic anterior paired lateral neurons facilitate olfactory reversal learning in Drosophila. Learn Mem 19: 478-486. doi:10.1101/lm.025726.112

Young J. 1962. Repeated reversal of training in Octopus. Q J Exp Psychol 14: 206-222. doi:10.1080/17470216208416539

Received January 31, 2019; accepted in revised form August 9, 2019. 


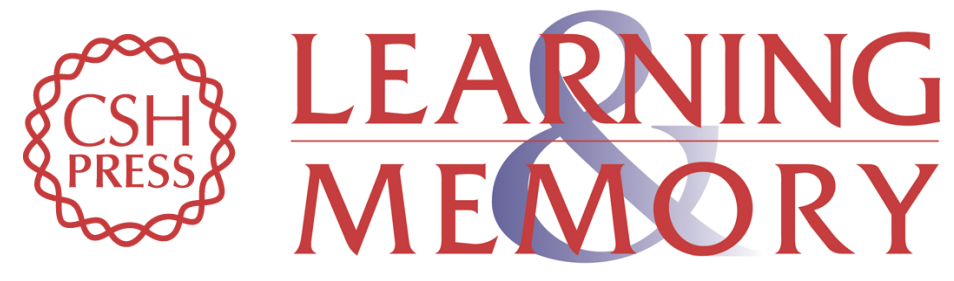

\section{Reversal learning in Drosophila larvae}

Nino Mancini, Sia Hranova, Julia Weber, et al.

Learn. Mem. 2019, 26:

Access the most recent version at doi:10.1101//m.049510.119

References This article cites 62 articles, 14 of which can be accessed free at: http://learnmem.cshlp.org/content/26/11/424.full.html\#ref-list-1

Creative This article is distributed exclusively by Cold Spring Harbor Laboratory Press for the Commons License first 12 months after the full-issue publication date (see http://learnmem.cshlp.org/site/misc/terms.xhtml). After 12 months, it is available under a Creative Commons License (Attribution-NonCommercial 4.0 International), as described at http://creativecommons.org/licenses/by-nc/4.0/.

Email Alerting Receive free email alerts when new articles cite this article - sign up in the box at the Service top right corner of the article or click here. 